\title{
ASPECTOS RELATIVOS À SAÚDE E AO MEIO AMBIENTE LIGADOS AO CONSUMO DE ALIMENTOS ORGÂNICOS
}

\author{
ASPECTS OF HEALTH AND THE \\ ENVIRONMENT RELATED TO \\ CONSUMPTION OF ORGANIC FOODS
}

\author{
Recebido: $26 / 04 / 2013$ \\ Aceite: 02/07/2013 \\ Edmilson Pinto de Albuquerque Júnior ${ }^{1}$ \\ José Carlos Lázaro da Silva Filho² \\ Josimar Souza Costa ${ }^{3}$ \\ Sandra Maria dos Santos ${ }^{4}$
}

\section{RESUMO}

Os alimentos orgânicos são propagados como alimentos saudáveis e ecologicamente corretos, e tornou-se relevante investigar esses dois construtos associados às intenções de compra dos consumidores. Este estudo busca investigar qual fator, entre elementos ligados ao meio ambiente e à busca por saúde, mais influencia as intenções de compra do consumidor de frutas, legumes e verduras (FLV) orgânicos no mercado cearense. Para tal fim, empreende-se uma pesquisa do tipo survey. A amostra é constituída de 200 respondentes. Os questionários foram aplicados entre os meses de fevereiro e março de 2012, em dois canais de distribuição de alimentos orgânicos, no município de Fortaleza - CE: feira agroecológica e supermercados. Para análise estatística dos dados, empreende-se a técnica da análise fatorial, com a utilização do software SPSS, versão 20. Os resultados sugerem que os fatores ligados à saúde apresentam maior peso sobre as intenções de compra desses alimentos. Do ponto de vista gerencial, as contribuições deste estudo residem na compreensão das variáveis determinantes do comportamento de compra de um mercado em ascensão, o que sugere bases para o desenvolvimento de estratégias, por parte dos agentes da cadeia produtiva, adequadas ao mercado analisado.

Palavras-chave: Consumo; Alimentos orgânicos; Consciência ambiental; Saúde.

\footnotetext{
${ }^{1}$ Possui graduação em Comunicação Social pela Universidade de Fortaleza - UNIFOR, especialização em Gerência Executiva de Marketing pela Universidade Federal do Ceará - UFC e mestrado em Administração e Controladoria pelo Programa de Pós-Graduação em Administração e Controladoria pela Universidade Federal do Ceará - UFC. Atualmente é professor da Faculdade Ateneu - FATE. Fortaleza, Ceará, Brasil. E-mail: edjunior05@yahoo.com.br.

2 Possui graduação em Engenharia Química pela Universidade Federal do Rio Grande do Sul - UFRGS, mestrado em Administração pela Universidade Federal do Rio Grande do Sul - UFRGS e doutorado em Planejamento Ambiental pela Technische Universität-Berlin. Atualmente é professor adjunto da Universidade Federal do Ceará - UFC. Fortaleza, Ceará, Brasil. E-mail: silvafilhode@ yahoo.com.br.

${ }^{3}$ Possui graduação em Administração pela Universidade de Fortaleza - UNIFOR e mestrado em Administração e Controladoria pela Universidade Federal do Ceará - UFC. Atualmente é professor assistente na Faculdade Ateneu - FATE. Fortaleza, Ceará, Brasil. E-mail: josimarsc@gmail.com.

${ }^{4}$ Possui graduação e mestrado em Ciências Econômicas pela Universidade Federal do Ceará - UFC e doutorado em Economia pela Universidade Federal de Pernambuco - UFPE. Atualmente é professora associada da Universidade Federal do Ceará - UFC. Fortaleza, Ceará, Brasil. E-mail: smsantos@ufc.br.
} 


\section{ABSTRACT}

Organic food is considered healthy and environmentally friendly, then becoming relevant the investigation about these two constructs associated to the purchase intention of consumers. This study sought to investigate which aspect, among those related to the environmental awareness and the pursuing of health, has greater influence on the shopping intentions of the consumer of organic fruits and vegetables (FV). To this end, it was applied a survey research type. The sample involved 200 interviewees. The questionnaires were applied from February to March, 2012, at two distribution channels of organic food in the city of Fortaleza, Ceará: agroecological fair and supermarkets. The factor analysis was employed for the statistical analysis of data by using the SPSS software, version 20. The results indicate that the aspects concerning health present more influence on the purchase intentions related to that type of food. From a managerial point of view, the contributions from this study reside in the comprehension of the determining variables of the purchase behavior of an ascending market, what suggests basis to the development of strategies, by the agents of the productive chain, adequate to the analyzed market.

Keywords: Consumption; Organic food; Environmental awareness; Health.

\section{INTRODUÇÃO}

As pessoas rotineiramente tomam decisões relativas à compra de alimentos. Essas escolhas se tornam mais significativas quando se leva em conta que a ingestão de alimentos está ligada à saúde. Dentro desse contexto, têm sido ainda amplamente divulgadas as implicações nocivas advindas do consumo de alimentos industrializados e/ou pobres em valores nutricionais, sendo estes apontados, dentre outras razões, como responsáveis por alguns dos problemas de saúde registrados na atualidade (HANSEN; MUKHERJEE; THOMSEN, 2011).

Concomitante a esse quadro, a questão do consumo alimentar também se tornou uma emblemática forma de expressão da consciência ambiental (KRISCHKE; TOMIELLO, 2009). Essa consciência pressupõe uma escolha legitimada pelo conhecimento do como e onde os alimentos são produzidos e de que maneira isso causará impacto no ecossistema. Assim, a sociedade tem demonstrado um crescente interesse na responsabilidade ambiental por trás dos alimentos consumidos; tendo os alimentos eticamente produzidos alcançado popularidade nas últimas décadas, o que ocasionou mudanças nos padrões tradicionais de consumo alimentar (MAHÉ, 2010; TSAKIRIDOU et al., 2008).

Em sintonia com esse contexto, e em razão de serem baseados em práticas de gestão que restauram e mantêm o equilíbrio ecológico, os denominados "alimentos orgânicos" se tornaram uma opção atrativa para muitos, o que tem elevado sua produção e consumo (GIL; GRACIA; SANCHEZ, 2000). Os alimentos orgânicos são cultivados e processados sem o uso de fertilizantes artificiais, pesticidas, herbicidas, fungicidas, reguladores de crescimento, aditivos, revestimentos químicos ou mesmo química nos materiais de embalagem (WINTER; DAVIS, 2006; SCHIFFERSTEIN; OUDE OPHUIS, 1998).

De acordo com Krischke e Tomiello (2009), os orgânicos refletem uma nova consciência que tem sido analisada, abrangendo questões múltiplas, tais como a preocupação com a ecologia e o bem-estar individual. Cahill, Morley e Powell (2010) confirmam que, historicamente, "meio ambiente" e "saúde" vêm sendo os construtos mais associados aos alimentos orgânicos. As pessoas estariam, portanto, cada vez mais interessadas em consumir esses alimentos, guiadas por consciência ambiental, saúde e, mesmo, por questões de ordem moral e social (ÖZCELIK; UÇAR, 2008; GIL; GRACIA; SANCHEZ, 2000).

Conforme Magnusson et al. (2003), essas questões, que vinculam os alimentos orgânicos a temas ligados à saúde e ao meio ambiente, possibilitam identificar dois perfis distintos de consumidores. Quando a preocupação com a saúde e o bem estar é declarada como a principal motivação para o consumo de orgânicos, tem-se uma motivação egoísta para esse comportamento. Em contrapartida, quando se consideram as questões relacionadas à preservação ambiental, 
a salubridade dos envolvidos em sua produção e a garantia de consumo às gerações futuras como a maior motivação para consumo destes alimentos, tem-se caracterizada uma relação altruísta de consumo, em que os benefícios para a sociedade falam mais à consciência.

Ciente da relevância de tais temas para a gestão contemporânea e para a sociedade, a pesquisa em questão tem como objetivo geral investigar qual fator, entre elementos ligados ao meio ambiente e à saúde, que mais influenciam as intenções de compra do consumidor de frutas, legumes e verduras (FLV) orgânicos no mercado cearense.

Além desta introdução, consta, no artigo, uma revisão bibliográfica na qual se busca contextualizar os orgânicos. Busca-se, ainda, traçar um panorama das pesquisas que vinculam os construtos "saúde" e "meio ambiente" ao consumo desses alimentos. Expõe-se também, na revisão bibliográfica, os principais construtos utilizados na pesquisa, advindos da Teoria do Comportamento Planejado de Ajzen (2008). Em seguida, tem-se a descrição da metodologia empregada nesta investigação, e explicam-se os resultados obtidos com as análises. Finaliza-se o artigo apresentando as conclusões e referências utilizadas.

\section{REFERENCIAL TEÓRICO}

\subsection{Alimentos orgânicos}

A expressão "alimento orgânico" foi utilizada pela primeira vez na década de 1940, embora o conceito subjacente seja muito mais antigo (JONES et al., 2001). Conforme exposto no artigo 2 미 Lei № 10.831 de 23 de dezembro de 2003, que dispõe sobre a agricultura orgânica no Brasil, "produto orgânico" é todo produto obtido, seja ele processado ou in natura, em sistema orgânico de produção agropecuário ou oriundo de processo extrativista sustentável e não prejudicial ao ecossistema local (BRASIL, 2003).

É característico dos sistemas orgânicos de produção a oferta de produtos isentos de contaminantes intencionais; a preservação da diversidade biológica dos ecossistemas naturais e a recomposição ou incremento da diversidade biológica dos ecossistemas modificados em que se insere o sistema de produção; o incentivo à integração entre os diferentes segmentos da cadeia produtiva e de consumo de produtos orgânicos; e a regionalização da produção e comércio desses produtos (BRASIL, 2007). Assim, os alimentos oriundos da agricultura orgânica são definidos pelas práticas e pelos insumos utilizados em seus processos produtivos e não por propriedades intrínsecas ao produto dali resultante (ZAKOWSKA-BIEMANS, 2011; SAHER et al., 2006).

Mesmo com uma participação ainda pequena no mercado agropecuário brasileiro, a produção de orgânicos tem evoluído fortemente (FLORES, 2011). O faturamento dos fornecedores desses alimentos, em 2010, foi de cerca de R\$ 500 milhões de acordo com a estimativa da Associação Brasileira de Orgânicos (BRASILBIO), que engloba os produtores, processadores e certificadores de orgânicos. Esse valor corresponde a apenas $0,2 \%$ dos $R \$ 255,3$ bilhões registrados pela Confederação da Agricultura e Pecuária do Brasil (CNA), como referentes ao valor bruto de toda a produção do setor agropecuário como um todo, em 2009. Em contrapartida, o mercado dos alimentos orgânicos cresce mais que o mercado tradicional (FLORES, 2011).

O Brasil tem potencial para se tornar um dos grandes produtores de orgânicos e para ser a porta de entrada destes produtos (MATIAS, 2011). A demanda em todo o mundo por orgânicos cresce acima de $30 \%$ ao ano e, no Brasil, cresce até $40 \%$, de acordo com a Associação Brasileira de Orgânicos (FLORES, 2011). Em maio de 2011, existiam cerca de 9,7 mil produtores orgânicos cadastrados no Ministério da Agricultura (BRITO, 2011). 


\subsection{0 consumo de alimentos orgânicos ligado à saúde e à consciência ambiental}

As crenças mais comuns acerca dos alimentos orgânicos são a de que eles são mais saudáveis e que seu modo de produção respeita requisitos de correção ambiental (WANDEL; BUGGE, 1997). A motivação para escolha desses alimentos em detrimento dos alimentos convencionais é baseada tanto nesses atributos como na crença de que os orgânicos contêm mais nutrientes do que os alimentos convencionais (ANNETT et al., 2008; MAGNUSSUM et al., 2003). O consumo de alimentos orgânicos é, assim, impulsionado pela preocupação com a saúde, a preocupação ambiental, pelas propriedades sensoriais dos alimentos, pela segurança alimentar e por preocupações éticas (ZAKOWSKA-BIEMANS, 2011; ESSOUSSI; ZAHAF, 2009; ÖZCELIK; UÇAR, 2008; MAGNUSSON et al., 2003; ZANOLI; NASPETTI, 2004).

De acordo com Magkos, Arvaniti e Zampela (2006), a segurança se tornou um dos atributos mais procurados nos alimentos atualmente. Isso implica motivações mais pessoais ou egoístas parecendo mais relevantes do que as razões altruístas (MAGNUSSON et al., 2003). Essa predominância do elemento individual em contraponto ao elemento coletivo poderia ser creditada ao fato de que o benefício individual é mais perceptível, e as pessoas tendem a levar mais em conta o benefício que vem em curto prazo e é mais visível para elas (MAGNUSSON et al., 2003). As pesquisas científicas também devem relacionar a busca por saúde e as crenças que ligam esta à busca pela beleza estética, uma vez que a preocupação com a aparência afeta fortemente hábitos alimentares, sendo, inclusive, fator por vezes predominante na escolha dos alimentos consumidos (HAYES; ROSS, 1987).

De acordo com Saher, Linderman e Ulla-Kaisa (2006), a maior parte das crenças declaradas acerca dos alimentos orgânicos é de natureza intuitiva. Muito do que se propaga ou se defende acerca desse tipo de alimento é baseado em intuição, e não em embasamento científico (CARHILL; MORLEY; POWELL, 2010; SAHER; LINDERMAN; ULLA-KAISA, 2006). Há poucos estudos científicos que dão, de fato, respaldo à crença generalizada de que os orgânicos são mais saudáveis e mais nutritivos que os alimentos ditos convencionais, embora a crença nisso seja forte (SAHER; LINDERMAN; ULLA-KAISA, 2006). Enquanto os benefícios para o meio ambiente não são questionados e são os mais divulgados ao comunicar os benefícios de sua produção, há um certo debate em curso sobre a salubridade e segurança dos orgânicos (ZAKOWSKA-BIEMANS, 2011).

A questão da percepção da salubridade dos orgânicos se relaciona com o componente cognitivo (crenças) dos indivíduos. Quando as pessoas têm incertezas em relação aos orgânicos, o peso de uma abordagem cognitiva é reduzido, e elas passam a confiar mais em seus sentimentos ao formar uma atitude em relação a estes alimentos diferenciados (AERTSENS et al., 2009). Uma pessoa com preocupações e crenças fortes em relação à saúde está mais predisposta a ter atitudes positivas em relação aos orgânicos.

Dessa forma, a consciência acerca da saúde pode indicar o grau de prontidão para empreender comportamentos mais saudáveis, sendo um construto mais amplo para indicar a presteza de uma pessoa para fazer alguma coisa em benefício de sua própria saúde (SCHIFFERSTEIN; OUDE OPHUIS, 1998; BECKER et al., 1977).

\subsection{Teoria do comportamento planejado}

De acordo com a Teoria do Comportamento Planejado - Theory of Planned Behaviour (TPB), o comportamento dos indivíduos é orientado por três crenças. As crenças comportamentais resultam em atitude (favorável ou não) em relação ao comportamento; as crenças norma- 
tivas resultam em pressão social perceptível (as normas subjetivas); e as crenças em controle podem facilitar ou dificultar a realização de um comportamento, resultando na percepção do controle que se tem sobre a ação (AJZEN, 1991). Juntos, esses elementos levam à formação de uma intenção comportamental, ou simplesmente intenção.

Quanto mais favorável a atitude e a norma subjetiva e quanto maior o controle comportamental percebido, mais forte deve ser a intenção da pessoa para executar o comportamento em questão. Segundo Ajzen (2008), por mais que as crenças de uma pessoa sejam infundadas, imprecisas ou tendenciosas, as suas atitudes, normas subjetivas e percepções de controle comportamental serão levadas a acompanhar de forma espontânea e razoável essas crenças, produzindo, assim, intenções comportamentais correspondentes, que poderão resultar em um comportamento. Comportamento este que será consistente com a tendência geral das crenças.

\section{METODOLOGIA}

Esta investigação, no tangente aos seus fins, é classificada como exploratória e descritiva. Optou-se pela amostragem não probabilística e intencional. $O$ instrumento de coleta utilizado foi um questionário estruturado e não disfarçado. Com o intuito de identificar possíveis problemas de interpretação, aprimorar, e aperfeiçoar o conteúdo de cada questão, empreendeu-se uma etapa de pré-teste.

O Quadro 1 resume a proposta geral da amostragem.

Quadro 1 - Proposta da amostragem para a pesquisa.

\begin{tabular}{|l|l|}
\hline População-alvo & Consumidores de FLV orgânicos em supermercados e feira agroecológica \\
\hline Método de coleta de dados & Survey \\
\hline Método de amostragem & Não probabilística intencional \\
\hline Tamanho da amostra & 200 entrevistados \\
\hline Abrangência & Cidade de Fortaleza-CE \\
\hline Período da coleta & Fevereiro e março de 2012 \\
\hline
\end{tabular}

Fonte: os autores

Os questionários foram aplicados entre os meses de fevereiro e março de 2012, em dois canais de distribuição de alimentos orgânicos no município de Fortaleza - CE: uma feira agroecológica e dezesseis supermercados. Os questionários foram aplicados após autorização dos estabelecimentos comerciais. Quatro pesquisadores, todos com experiência anterior em pesquisas de campo, foram especificamente treinados para lidar com o tema da pesquisa. Quando da aplicação dos questionários, os respondentes, se adequados à pergunta filtro, eram convidados a respondê-lo até o fim. Um tempo médio de 15 minutos por pessoa foi verificado para responder aos questionários.

Optou-se por elaborar o questionário a partir de instrumentos já validados e que apresentavam vínculo direto com o tema aqui proposto. O questionário foi composto por nove blocos. Os sete primeiros blocos guardam relação direta com a Teoria do Comportamento Planejado (TPB) de Ajzen (2008) e buscam mensurar os construtos que compõem essa teoria. O oitavo bloco busca mensurar a frequência de compra dos produtos orgânicos. $\mathrm{O}$ último bloco investiga o perfil sociodemográfico da amostra.

A maior parte do questionário é composta por escala de sete pontos, a Escala Likert, com a utilização dos pólos "concordo totalmente"/ "discordo totalmente" em um contínuo; entretanto, tem-se também a utilização de questões com escalas de diferencial semântico, com a utilização de adjetivos bipolares, tais como satisfeito/insatisfeito ou danoso/benéfico, como pontos finais em um contínuo. 
No Quadro 2, a seguir, é possível visualizar a proposta de cada um dos nove blocos.

Quadro 2 - Resumo do instrumento de coleta

\begin{tabular}{|c|c|c|c|c|}
\hline Bloco & Construto & $\begin{array}{l}\text { Quantiade } \\
\text { de itens }\end{array}$ & Referência & Objetivo \\
\hline 1 & $\begin{array}{l}\text { Atitudes em relação ao } \\
\text { meio ambiente (ATMA) }\end{array}$ & 05 & $\begin{array}{l}\text { Gil; Gracia; } \\
\text { Sanchez (2000) }\end{array}$ & $\begin{array}{l}\text { Mensurar crenças e sentimentos em } \\
\text { relação ao construto meio ambiente. }\end{array}$ \\
\hline 2 & $\begin{array}{l}\text { Motivações e crenças li- } \\
\text { gadas à saúde (MCS) }\end{array}$ & 09 & $\begin{array}{l}\text { Chen (2007) e } \\
\text { Schifferstein e } \\
\text { Oude Ophuis } \\
\text { (1998) }\end{array}$ & Mensurar o construto saúde. \\
\hline 3 & $\begin{array}{l}\text { Atitudes em relação aos } \\
\text { orgânicos (ATO) }\end{array}$ & 09 & $\begin{array}{l}\text { Gil; Gracia; } \\
\text { Sanchez (2000) }\end{array}$ & $\begin{array}{l}\text { Mensurar crenças e sentimentos em } \\
\text { relação aos alimentos orgânicos. }\end{array}$ \\
\hline 4 & $\begin{array}{l}\text { Atitudes em relação à } \\
\text { compra de FLV orgânicos } \\
\text { (ATC) }\end{array}$ & 06 & Hoppe (2010) & $\begin{array}{l}\text { Mensurar as crenças, sentimentos e } \\
\text { avaliações morais em relação a com- } \\
\text { pra de FLV orgânicos. }\end{array}$ \\
\hline 5 & Normas subjetivas (NS) & 02 & \multirow{2}{*}{ Chen (2007) } & $\begin{array}{l}\text { Mensurar o poder social que influen- } \\
\text { cia as intenções. }\end{array}$ \\
\hline 6 & $\begin{array}{l}\text { Controle comportamen- } \\
\text { tal percebido (CCP) }\end{array}$ & 03 & & $\begin{array}{l}\text { Mensurar preditores para o controle } \\
\text { real da ação e de barreiras percebidas. }\end{array}$ \\
\hline 7 & $\begin{array}{l}\text { Intenções comportamen- } \\
\text { tais (IC) }\end{array}$ & 02 & $\begin{array}{l}\text { Shaharudin et al } \\
(2010)\end{array}$ & $\begin{array}{l}\text { Mensurar expectativas de comporta- } \\
\text { mento dos entrevistados em relação à } \\
\text { compra. }\end{array}$ \\
\hline 8 & $\begin{array}{l}\text { Frenquência de compra } \\
\text { de FLV orgânicos }\end{array}$ & 04 & O autor & Identificar a frequência de compra. \\
\hline 9 & Perfil sociodemográfico & 07 & O autor & Traçar um perfil do entrevistado. \\
\hline
\end{tabular}

Fonte: os autores.

As variáveis observáveis foram codificadas para melhor representação e compreensão. Quadro 3 apresenta a codificação, em sequência, das variáveis observáveis, tomando por base sua alocação em cada construto.

Quadro 3-Codificação das variáveis observáveis de cada construto

\begin{tabular}{|l|l|}
\hline $\begin{array}{c}\text { Código da } \\
\text { variável }\end{array}$ & Variável \\
\hline atma $\mathbf{1}$ & O desenvolvimento atual está destruindo o meio ambiente. \\
\hline atma $\mathbf{2}$ & Prefiro consumir produtos reciclados. \\
\hline atma $\mathbf{3}$ & Faço a coleta seletiva do meu lixo. \\
\hline atma $\mathbf{4}$ & A menos que façamos algo, os danos ambientais serão irreversíveis. \\
\hline atma $\mathbf{5}$ & Pratico ações de preservação ambiental. \\
\hline mcs $\mathbf{1}$ & É importante para mim que a comida que eu consumo diariamente me mantenha saudável. \\
\hline mcs $\mathbf{2}$ & Eu realmente não fico pensando o tempo todo se tudo o que eu faço é saudável. \\
\hline mcs $\mathbf{3}$ & É importante para mim que a comida que eu consumo diariamente seja nutritiva. \\
\hline mcs $\mathbf{4}$ & $\begin{array}{l}\text { É importante para mim que a comida que eu consumo diariamente seja boa para minha pele, } \\
\text { dentes, cabelo. }\end{array}$ \\
\hline mcs $\mathbf{5}$ & Acredito que seja importante saber bem como se alimentar de maneira saudável. \\
\hline mcs $\mathbf{6}$ & Tenho a impressão de que as outras pessoas prestam mais atenção à sua saúde do que eu. \\
\hline mcs $\mathbf{7}$ & Não fico o tempo todo me perguntando se as coisas que eu como são boas pra mim. \\
\hline mcs $\mathbf{8}$ & Tenho a impressão que eu me sacrifico muito em prol da minha saúde. \\
\hline mcs $\mathbf{9}$ & $\begin{array}{l}\text { Estou preparado para abdicar de muitas coisas e me alimentar da maneira mais saudável pos- } \\
\text { sivel. }\end{array}$ \\
\hline ato $\mathbf{1}$ & Alimentos orgânicos são mais saudáveis. \\
\hline
\end{tabular}




\begin{tabular}{|c|c|}
\hline $\begin{array}{l}\text { Código da } \\
\text { variável }\end{array}$ & Variável \\
\hline ato 2 & Alimentos orgânicos têm qualidade superior. \\
\hline ato 3 & Alimentos orgânicos são uma fraude. \\
\hline ato 4 & Alimentos orgânicos são mais gostosos. \\
\hline ato 5 & Alimentos orgânicos são piores que os alimentos convencionais. \\
\hline ato 6 & Alimentos orgânicos são mais caros. \\
\hline ato 7 & Alimentos orgânicos são mais bonitos \\
\hline ato 8 & Alimentos orgânicos não fazem mal. \\
\hline ato 9 & Alimentos orgânicos são apenas moda. \\
\hline atc 1 & $\begin{array}{l}\text { Comprar FLV orgânicos em vez dos convencionais me faria sentir que estou fazendo algo "po- } \\
\text { liticamente correto". }\end{array}$ \\
\hline atc 2 & Comprar FLV orgânicas ao invés dos convencionais me faria sentir uma pessoa melhor. \\
\hline atc 3 & $\begin{array}{l}\text { Comprar FLV orgânicos ao invés dos convencionais faria eu me sentir como se estivesse con- } \\
\text { tribuindo para algo melhor. }\end{array}$ \\
\hline atc 4 & Comprar FLV orgânicos em vez dos convencionais seria... (danoso/benéfico) \\
\hline atc 5 & Comprar FLV orgânicos em vez dos convencionais seria... (tolice-sábio) \\
\hline atc 6 & Comprar FLV orgânicos em vez dos convencionais me faria sentir...(satisfeito/insatisfeito) \\
\hline ns 1 & $\begin{array}{l}\text { A maioria das pessoas que são importantes para mim acha que eu deveria } \\
\text { alimentos orgânicos. (definitivamente evitar/comprar) }\end{array}$ \\
\hline ns 2 & $\begin{array}{l}\text { Grande parte das pessoas próximas a mim acha que eu deveria } \\
\text { tos orgânicos. (definitivamente evitar/comprar) }\end{array}$ \\
\hline $\operatorname{ccp} 1$ & $\begin{array}{l}\text { Se frutas, legumes e verduras orgânicos estiverem disponíveis para compra, nada me impedi- } \\
\text { ria de comprá-los, caso eu quisesse. }\end{array}$ \\
\hline $\operatorname{ccp} 2$ & Eu tenho total controle sobre uma eventual compra de frutas, legumes e verduras orgânicos. \\
\hline $\operatorname{ccp} 3$ & $\begin{array}{l}\text { Se eu quisesse, eu poderia facilmente comprar frutas, legumes e verduras orgânicas em vez } \\
\text { dos convencionais. }\end{array}$ \\
\hline ic 1 & Eu planejo consumir FLV orgânicos em breve. \\
\hline ic 2 & Eu pretendo comprar FLV orgânicos nos próximos quinze dias. \\
\hline
\end{tabular}

A mensuração e análise dos construtos que constam no questionário objetivaram responder ao objetivo geral da pesquisa e reconhecer que, pela ação conjunta dos construtos, é possível obter uma resposta coerente, assim como a própria TPB presume que é da ação conjunta entre a atitude, a norma subjetiva e o controle comportamental percebido que se pode prever (ainda que com certo grau de incerteza) um comportamento. Para proceder à análise dos dados, empreendeu-se a análise fatorial com a utilização do software estatístico SPSS, versão 20.0.

\section{ANÂLISE E DISCUSSÃO DOS RESULTADOS}

\subsection{Caracterização da amostra}

A Tabela 1 apresenta o perfil sociodemográfico da amostra pesquisada. 
Tabela 1 - Caracterização sócio-demográfica da amostra.

\begin{tabular}{|c|c|c|}
\hline \multicolumn{2}{|c|}{ Caracterização } & $\begin{array}{l}\text { Porcentagem da amos- } \\
\text { tra (\%) }\end{array}$ \\
\hline Gênero & & \\
\hline & Masculino & 32 \\
\hline & Feminino & 68 \\
\hline \multicolumn{3}{|c|}{ Faixa Etária } \\
\hline & 18 a 25 anos & 18 \\
\hline & 26 a 35 anos & 19 \\
\hline & 36 a 45 anos & 18,5 \\
\hline & 46 a 55 anos & 26 \\
\hline & 56 a 65 anos & 13,5 \\
\hline & Mais de 65 anos & 5 \\
\hline \multicolumn{3}{|c|}{ Grau de escolaridade } \\
\hline & Fundamental & 1,50 \\
\hline & Fundamental incompleto & 1 \\
\hline & Ensino médio & 17 \\
\hline & Ensino médio incompleto & 2 \\
\hline & Superior & 38,5 \\
\hline & Superior incompleto & 16 \\
\hline & Pós-graduação & 24 \\
\hline \multicolumn{3}{|c|}{ Estado civil } \\
\hline & Solteiro (a) & 35,5 \\
\hline & Casado (a) & 53,5 \\
\hline & Separado ou divorciado (a) & 7 \\
\hline & Viúvo (a) & 4 \\
\hline \multicolumn{3}{|c|}{ Renda Familiar mensal } \\
\hline & Até $1.000,00$ & 13 \\
\hline & De $1.001,00$ a $3.000,00$ & 17 \\
\hline & De $3.001,00$ a $5.000,00$ & 29 \\
\hline & De $5.001,00$ a $7.000,00$ & 15,5 \\
\hline & Mais de $7.001,00$ & 25,5 \\
\hline
\end{tabular}

Fonte: dados da pesquisa 2012.

Pode-se observar a predominância do sexo feminino na amostra: das 200 pessoas entrevistadas 136 foram mulheres (68\%); enquanto 64 (32\%), homens. No tangente à faixa etária dos respondentes, constatou-se que há uma ligeira equiparação entre as faixas de 18 a 25 anos (18\%), 26 a 35 anos (19\%), e 36 a 45 anos (18,5\%). Um número de 52 respondentes (26\%) encontra-se na faixa entre 46 a 55 anos e representa a maior porcentagem nessa categoria. Tem-se, ainda, que 27 respondentes $(13,5 \%)$ declararam estar na faixa entre 56 a 65 anos, enquanto que apenas 10 respondentes (5\%) dos 200 têm mais de 65 anos de idade.

Foi solicitado, ainda, aos respondentes que indicassem a frequência na qual costumam comprar frutas, legumes e verduras (FLV) orgânicos. Os resultados são visualizados no Gráfico 1.

Gráfico 1 - Frequência de compra de FLV orgânicos
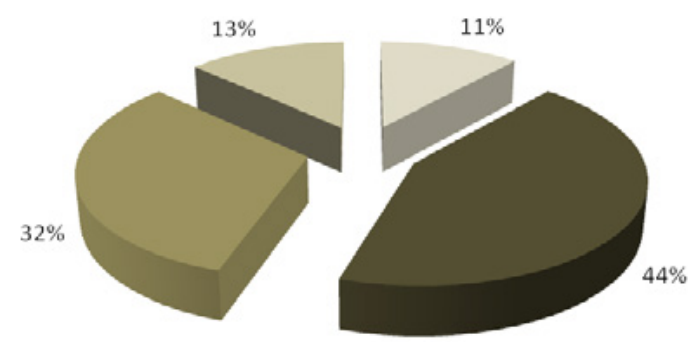

Diariamente

- Semanalmente

- De vez em quando

E Raramente

Fonte: dados da pesquisa 2012. 
Observa-se que $44 \%$ dos respondentes afirmaram que compram apenas semanalmente, e $32 \%$ declararam que compram de vez em quando. Tem-se que $13 \%$ dos entrevistados afirmaram comprar "raramente", e apenas $11 \%$ da amostra declarou a opção "diariamente" como a mais adequada a sua realidade de compra.

\subsection{Análise descritiva dos construtos}

Nas tabelas desta seção, visualizam-se os construtos analisados, suas variáveis observáveis, suas médias e seus desvios-padrão, com base nos resultados da pesquisa. Observa-se, na Tabela 2, a seguir, o construto "atitudes em relação ao meio ambiente", um dos fatores mais associados ao consumo de orgânicos conforme exposto na revisão bibliográfica.

Tabela 2 - Estatística descritiva das atitudes em relação ao meio ambiente.

\begin{tabular}{clcc}
\hline Construto & \multicolumn{1}{c}{ Variável } & Média & $\begin{array}{c}\text { Desvio } \\
\text { padrão }\end{array}$ \\
\hline & O desenvolvimento atual está destruindo o meio ambiente. & 6,25 & 1,34 \\
Atitudes em & Prefiro consumir produtos reciclados. & 5,12 & 1,75 \\
relação ao meio Faço a coleta seletiva do meu lixo. & 4,75 & 2,25 \\
ambiente & A menos que façamos algo, os danos ambientais serão irreversíveis. & 6,38 & 1,35 \\
& Pratico ações de preservação ambiental. & 5,26 & 1,63 \\
\hline
\end{tabular}

Fonte: dados da pesquisa 2012.

No construto "Atitudes em relação ao meio ambiente", as médias mais elevadas pertencem aos indicadores "o desenvolvimento atual está destruindo o meio ambiente" e "a menos que façamos algo, os danos ambientais serão irreversíveis", com os valores 6,25 e 6,38, respectivamente, revelando, assim, a concordância dos respondentes quanto à relevância das ações ativas e reativas do homem em relação ao meio ambiente, tomando-o como responsável pelo problema e como o agente catalisador da mudança dos problemas ambientais. Apesar dos altos níveis de atitudes favoráveis e intenções em prol do bem-estar ecológico serem comumente registrados em pesquisas, tal fato não tem necessariamente influenciado, na mesma intensidade, ações pró-ambientais, conforme revelam as pesquisas de Dunlap e Scarce (1991) e Tarrant e Cordelle (1997).

Observa-se, na Tabela 3, a seguir, o construto "motivações e crenças ligados à saúde", o outro fator mais associado ao consumo de orgânicos.

Tabela 3 - Estatística descritiva das motivações e crenças ligadas à saúde

\begin{tabular}{|c|c|c|c|}
\hline Construto & Variável & Média & $\begin{array}{l}\text { Desvio } \\
\text { padrão }\end{array}$ \\
\hline \multirow{8}{*}{$\begin{array}{l}\text { Motivações } \\
\text { e crenças } \\
\text { ligadas à } \\
\text { saúde }\end{array}$} & $\begin{array}{l}\text { É importante para mim que a comida que eu consumo diariamente me } \\
\text { mantenha saudável. }\end{array}$ & 6,70 & 0,81 \\
\hline & \multirow{2}{*}{$\begin{array}{l}\text { Eu realmente não fico pensando o tempo todo se tudo o que eu faço é saudável. } \\
\text { É importante para mim que a comida que eu consumo diariamente seja nutritiva. } \\
\text { É importante para mim que a comida que eu consumo diariamente seja boa } \\
\text { para minha pele, meus dentes, meu cabelo. }\end{array}$} & $\begin{array}{l}4 \\
6\end{array}$ & $\begin{array}{l}2,05 \\
1,12\end{array}$ \\
\hline & & 6,24 & 1,33 \\
\hline & $\begin{array}{l}\text { Acredito que seja importante saber bem como se alimentar de maneira } \\
\text { saudável. }\end{array}$ & 6,67 & 0,74 \\
\hline & $\begin{array}{l}\text { Tenho a impressão de que as outras pessoas prestam mais atenção à sua } \\
\text { saúde do que eu. }\end{array}$ & 3,88 & 2,18 \\
\hline & $\begin{array}{l}\text { Não fico o tempo todo me perguntando se as coisas que eu como são boas } \\
\text { pra mim. }\end{array}$ & 4,22 & 2,10 \\
\hline & Tenho a impressão que eu me sacrifico muito em prol da minha saúde. & 3,27 & 1,90 \\
\hline & $\begin{array}{l}\text { Estou preparado para abdicar de muitas coisas e me alimentar da maneira } \\
\text { mais saudável possivel. }\end{array}$ & 5,38 & 1,72 \\
\hline
\end{tabular}


Enquadrados no construto "Motivações e crenças ligadas à saúde", observa-se que os valores mais elevados para a média (6,70 e 6,67, respectivamente) pertencem aos itens "É importante para mim que a comida que eu consumo diariamente me mantenha saudável" e "Acredito que seja importante saber bem como se alimentar de maneira saudável". Essas médias elevadas, considerando que a escala utilizada no questionário foi de 7 pontos, revelam que os respondentes associam positivamente uma boa alimentação à saúde. Ressalte-se que o "crédito" dado à saúde como fator predominante nas escolhas de orgânicos, à frente das preocupações com o bem-estar do planeta - tem sido elevado, conforme já afirmaram, dentre outros, Essoussi e Zahaf (2009).

A Tabela 4, a seguir, apresenta os resultados referentes às atitudes da amostra no tangente aos próprios alimentos orgânicos.

Tabela 4 - Estatística descritiva das atitudes em relação aos alimentos orgânicos

\begin{tabular}{|c|c|c|c|}
\hline Construto & Variável & Média & $\begin{array}{l}\text { Desvio } \\
\text { padrão }\end{array}$ \\
\hline \multirow{9}{*}{$\begin{array}{c}\text { Atitudes em } \\
\text { relação aos } \\
\text { alimentos orgâ- } \\
\text { nicos }\end{array}$} & Alimentos orgânicos são mais saudáveis. & 6,63 & 0,85 \\
\hline & Alimentos orgânicos têm qualidade superior. & 6,34 & 1,11 \\
\hline & Alimentos orgânicos são uma fraude. & 1,84 & 1,38 \\
\hline & Alimentos orgânicos são mais gostosos. & 5,11 & 1,91 \\
\hline & Alimentos orgânicos são piores que os alimentos convencionais. & 1,80 & 1,51 \\
\hline & Alimentos orgânicos são mais caros. & 6,50 & 1,12 \\
\hline & Alimentos orgânicos são mais bonitos & 5,17 & 2,01 \\
\hline & Alimentos orgânicos não fazem mal. & 5,59 & 1,76 \\
\hline & Alimentos orgânicos são apenas moda. & 2.04 & 1,54 \\
\hline
\end{tabular}

Fonte: dados da pesquisa 2012.

Verifica-se, por meio da análise das médias do construto "Atitudes em relação aos alimentos orgânicos", uma forte concordância quanto aos alimentos orgânicos serem salubres, pois os itens "os alimentos orgânicos são mais saudáveis" e "os alimentos orgânicos têm qualidade superior" apresentam médias de 6,63 e 6,34, respectivamente. As crenças mais comuns acerca dos alimentos orgânicos têm sido a de que eles são mais saudáveis e que seu modo de produção respeita requisitos de correção ambiental (WANDEL; BUGGE, 1997). A motivação para escolha desses alimentos é baseada tanto nesses atributos como na crença de que eles contêm mais nutrientes do que os alimentos convencionais (ANNETT et al., 2008; MAGNUSSUM et al., 2003).

Ainda no que se refere a esse construto, outras médias merecem atenção: os itens "alimentos orgânicos são uma fraude", "alimentos orgânicos são piores que os convencionais" e "alimentos orgânicos são apenas moda" apresentaram média que revelam expressiva discordância dos entrevistados em relação a essas afirmações, com valores de 1,84, 1,80 e 2,04, respectivamente. As médias reveladas no construto "Atitudes em relação aos orgânicos" acabam por revelar que os consumidores têm uma avaliação positiva em relação a esses alimentos. Muito embora seja importante destacar, ainda, o fato de que, de acordo com a pesquisa, os orgânicos são percebidos como alimentos mais caros, como revela a média 6,50 , associada ao item que expressa essa afirmativa. Essa observação está em sintonia com pesquisas que revelam que, entre as principais dificuldades declaradas ao consumo de alimentos orgânicos, está o preço elevado (AERSTSENS et al., 2009; SAHER; LINDERMAN; ULLA-KAISA, 2006; PADEL; FOSTER, 2005).

A Tabela 5, a seguir, apresenta os resultados referentes aos construtos da teoria do comportamento planejado. 
Tabela 5 - Estatística descritiva dos construtos ligados a teoria do comportamento planejado.

\begin{tabular}{|c|c|c|c|}
\hline Construto & Variável & Média & $\begin{array}{l}\text { Desvio } \\
\text { padrão }\end{array}$ \\
\hline \multirow{6}{*}{$\begin{array}{l}\text { Atitudes em re- } \\
\text { lação à compra } \\
\text { de FLV orgâni- } \\
\text { cos }\end{array}$} & $\begin{array}{l}\text { Comprar FLV orgânicos em vez dos convencionais me faria sentir } \\
\text { que estou fazendo algo "politicamente correto". }\end{array}$ & 5,72 & 1,76 \\
\hline & $\begin{array}{l}\text { Comprar FLV orgânicos em vez dos convencionais me faria sentir } \\
\text { uma pessoa melhor. }\end{array}$ & 5,32 & 2,04 \\
\hline & $\begin{array}{l}\text { Comprar FLV orgânicos em vez dos convencionais faria eu me sentir } \\
\text { como se estivesse contribuindo para algo melhor. }\end{array}$ & 6,03 & 1,46 \\
\hline & Comprar FLV orgânicos em vez dos convencionais seria... & 6,57 & 0,90 \\
\hline & Comprar FLV orgânicos em vez dos convencionais seria... & 6,50 & 0,93 \\
\hline & Comprar FLV orgânicos em vez dos convencionais me faria sentir... & 6,41 & 1,09 \\
\hline \multirow{2}{*}{$\begin{array}{l}\text { Normas subje- } \\
\text { tivas }\end{array}$} & $\begin{array}{l}\text { A maioria das pessoas que são importantes para mim acham que } \\
\text { eu deveria_alimentos orgânicos. }\end{array}$ & 5,67 & 1,70 \\
\hline & $\begin{array}{c}\text { Grande parte das pessoas próximas a mim acham que eu deveria } \\
\text { alimentos orgânicos. }\end{array}$ & 5,66 & 1,62 \\
\hline \multirow{3}{*}{$\begin{array}{l}\text { Controle com- } \\
\text { portamental } \\
\text { percebido orgâ- } \\
\text { nicos }\end{array}$} & $\begin{array}{l}\text { Se frutas, legumes e verduras orgânicos estiverem disponíveis para } \\
\text { compra, nada me impediria de comprá-los, caso eu quisesse. }\end{array}$ & 5,85 & 1,46 \\
\hline & $\begin{array}{l}\text { Eu tenho total controle sobre uma eventual compra de frutas, legu- } \\
\text { mes e verduras orgânicos. }\end{array}$ & 5,45 & 2,02 \\
\hline & $\begin{array}{l}\text { Se eu quisesse, eu poderia facilmente comprar frutas, legumes e } \\
\text { verduras orgânicas ao invés dos convencionais. }\end{array}$ & 5,03 & 2,09 \\
\hline \multirow{2}{*}{$\begin{array}{l}\text { Intenções de } \\
\text { compra }\end{array}$} & Eu planejo consumir FLV orgânicos em breve. & 6,14 & 1,23 \\
\hline & Eu pretendo comprar FLV orgânicos nos próximos quinze dias. & 5,64 & 1,83 \\
\hline
\end{tabular}

Fonte: dados da pesquisa 2012.

No que se refere ao construto "atitudes em relação à compra de frutas, legumes e verduras orgânicos", os maiores valores expressam e reforçam a concordância com o construto anterior, em que se constata a percepção positiva quanto aos orgânicos. Os itens "comprar FLV orgânicos em vez dos convencionais seria... (danoso/benéfico)" e "comprar FLV orgânicos em vez dos convencionais seria... (tolice/sábio)" mostraram médias que tendem fortemente para os extremos "benéfico" e "sábio", com 6,57 e 6,50, respectivamente. Isso indica que, na avaliação dos respondentes, a compra de alimentos orgânicos é vista como uma ação positiva.

\subsection{Análise fatorial}

A análise fatorial se refere a métodos estatísticos multivariados, cujo propósito é a definição de uma estrutura subjacente em uma matriz de dados. A fatorial analisa correlações entre uma quantidade grande de variáveis e define um conjunto de dimensões latentes comuns. É um procedimento, portanto, de redução da dimensão dos dados originais, que visa a identificar um pequeno número de fatores que explique a maior parte da variação observada de um número grande de variáveis (HAIR JR et al, 2005).

No tocante ao padrão de correlação entre as variáveis, observou-se que a matriz de correlações exibiu a maior parte dos coeficientes com valor acima 0,30, constatando, assim, também a adequabilidade dos dados à fatorial. A análise de componentes principais foi conduzida, nos 36 itens do questionário, com rotação ortogonal (Varimax), na amostra de 200 respondentes para verificação de existência de dimensões latentes nos dados. No que se refere aos testes de adequação da amostra, a Tabela 6 sintetiza o diagnóstico referente à adequação. 
Tabela 6 - Testes de adequação da amostra

\begin{tabular}{|c|c|c|}
\hline \multicolumn{3}{|c|}{ KMO e Barlett } \\
\hline Medida Kaiser-Meyer-Olkin de ac & quação de amostragem. & 751 \\
\hline Teste de esfericidade de Bartlett & $\begin{array}{l}\text { Chi-quadrado aprox. } \\
\text { GI (graus de liberdade) } \\
\text { Sig. }\end{array}$ & $\begin{array}{r}2347,347 \\
630 \\
000 \\
\end{array}$ \\
\hline
\end{tabular}

Fonte: dados da pesquisa 2012.

A medida de Kaiser-Meyer-Olkin verificou a adequação amostral para a análise (KMO $=0,751)$, e todos os valores de KMO para os itens individualmente se mostraram adequados. $\mathrm{O}$ teste de esfericidade de Bartlett $\left[x^{2}(630)=2347,347\right.$, $p$ menor que 0,001$]$ indicou que as correlações entre os itens foram suficientes para indicar a apropriação da análise. Essa análise inicial revelou que onze componentes obedeceram ao critério de Kaiser do autovalor ("Eigenvalue") maior que 1, conforme observado na Tabela 7, a seguir.

Tabela 7 - Adequação ao critério Kaiser do autovalor

\begin{tabular}{|c|c|c|c|c|c|c|c|c|c|}
\hline \multirow{2}{*}{$\begin{array}{c}\text { Compo- } \\
\text { nente }\end{array}$} & \multicolumn{3}{|c|}{ Valores próprios iniciais } & \multicolumn{3}{|c|}{$\begin{array}{c}\text { Somas de extração de } \\
\text { carregamentos ao quadrado }\end{array}$} & \multicolumn{3}{|c|}{$\begin{array}{c}\text { Somas rotativas de } \\
\text { carregamentos ao quadrado }\end{array}$} \\
\hline & Total & $\begin{array}{c}\% \text { de } \\
\text { variação }\end{array}$ & $\%$ cumulativa & Total & $\begin{array}{c}\% \text { de } \\
\text { variação }\end{array}$ & $\%$ cumulativa & Total & $\begin{array}{c}\% \text { de } \\
\text { variação }\end{array}$ & $\%$ cumulativa \\
\hline 1 & 6,694 & 18,596 & 18,596 & 6,694 & 18,596 & 18,596 & 3,774 & 10,482 & 10,482 \\
\hline 2 & 2,526 & 7,018 & 25,613 & 2,526 & 7,018 & 25,613 & 3,076 & 8,544 & 19,026 \\
\hline 3 & 2,146 & 5,962 & 31,575 & 2,146 & 5,962 & 31,575 & 3,050 & 8,471 & 27,497 \\
\hline 4 & 1,899 & 5,274 & 36,849 & 1,899 & 5,274 & 36,849 & 1,942 & 5,393 & 32,891 \\
\hline 5 & 1,697 & 4,713 & 41,562 & 1,697 & 4,713 & 41,562 & 1,869 & 5,192 & 38,083 \\
\hline 6 & 1,635 & 4,541 & 46,104 & 1,635 & 4,541 & 46,104 & 1,718 & 4,771 & 42,854 \\
\hline 7 & 1,399 & 3,885 & 49,989 & 1,399 & 3,885 & 49,989 & 1,677 & 4,659 & 47,513 \\
\hline 8 & 1,312 & 3,646 & 53,634 & 1,312 & 3,646 & 53,634 & 1,602 & 4,450 & 51,963 \\
\hline 9 & 1,215 & 3,376 & 57,011 & 1,215 & 3,376 & 57,011 & 1,434 & 3,985 & 55,947 \\
\hline 10 & 1,187 & 3,298 & 60,308 & 1,187 & 3,298 & 60,308 & 1,354 & 3,760 & 59,707 \\
\hline 11 & 1.107 & 3.075 & 63,384 & 1.107 & 3,075 & 63,384 & 1,323 & 3.676 & 63,384 \\
\hline
\end{tabular}

Método de extração: análise do componente principal.

Em conjunto, esses onze explicam 63,38\% da variância. Considerando-se o tamanho da amostra ( $N=200$ ) e o critério de Kaiser, esse foi o número de componentes mantido na análise, além de se estar trabalhando com 36 variáveis observadas, ou seja, dentro do limite aceitável, que é entre 20 e 50 variáveis.

Pretende-se que a visualização dos itens do questionário na forma codificada torne mais fácil a leitura dos dados; como na Tabela 8, em que se observa a representação geral dos fatores obtidos.

Tabela 8 - Matriz de componente rotativa

\begin{tabular}{|c|c|c|c|c|c|c|c|c|c|c|c|}
\hline Variável & & & & & & Con & nte & & & & \\
\hline & 1 & 2 & 3 & 4 & 5 & 6 & 7 & 8 & 9 & 10 & 11 \\
\hline mcs4 & 811 & & & & & & & & & & \\
\hline mcs1 & 751 & & & & & & & & & & \\
\hline mcs3 & ,751 & & & & & & & & & & \\
\hline mcs5 &, 623 & & & & & & & & & & \\
\hline atma5 & ,568 & & & & & & & & & & \\
\hline $\operatorname{mcs} 9$ & ,565 & & & & & & & & & & \\
\hline ato4 & & & & & & & & & & & \\
\hline atc3 & & 777 & & & & & & & & & \\
\hline atc1 & & ,756 & & & & & & & & & \\
\hline atc2 & & ,726 & & & & & & & & & \\
\hline atc5 & & ,536 & ,482 & & & & & & & & \\
\hline
\end{tabular}




\begin{tabular}{|c|c|c|c|c|c|c|c|c|c|c|c|}
\hline Variável & & & & & & Compon & nte & & & & \\
\hline & 1 & 2 & 3 & 4 & 5 & 6 & 7 & 8 & 9 & 10 & 11 \\
\hline ato8 & & & & & & & & & & & \\
\hline ato3 & & & -,781 & & & & & & & & \\
\hline ato1 & & & ,708 & & & & & & & & \\
\hline ato9 & & &,- 523 & & & & & & &,- 489 & \\
\hline atc4 & & ,419 & ,515 & & & & & & & & \\
\hline atc6 & ,426 & & ,509 & & & & & & & & \\
\hline ato2 & & & ,465 & & & & & & & & \\
\hline ns1 & & & & ,865 & & & & & & & \\
\hline ns2 & & & & 857 & & & & & & & \\
\hline mcs7 & & & & & 770 & & & & & & \\
\hline mcs6 & & & & & 651 & & & & & & \\
\hline mcs2 & & & & & ,527 & &,- 433 & & & & \\
\hline atma4 & & & & & & ,784 & & & & & \\
\hline atma1 & & & & & & ,593 & & & & & \\
\hline ic2 & & & & & & & 789 & & & & \\
\hline ic1 & & & & & & & ,489 & & & & \\
\hline cсp1 & & & & & & & & ,736 & & & \\
\hline сср3 & & & & & & & & ,602 & & & \\
\hline mcs8 & & & & & & -,419 & &,- 469 & & & \\
\hline atma2 & & & & & & & & & ,663 & & \\
\hline $\operatorname{ccp} 2$ & & & & & & & & & 652 & & \\
\hline ato6 & & & & & & & & & & 787 & \\
\hline atma3 & & & & & & & & & & & 737, \\
\hline ato 7 & & & & & & & & & & & -,509 \\
\hline ato5 & & & & & 416 & & & & & & 494 \\
\hline & & & odo & & :ão: Ar & $\begin{array}{l}\text { se do } \\
\text { s com }\end{array}$ & $\begin{array}{l}\text { pon } \\
\text { nali }\end{array}$ & $\begin{array}{l}\text { princi } \\
\text { o de Ka }\end{array}$ & & & \\
\hline
\end{tabular}

Observa-se que os fatores agrupados guardam, em grande medida, vínculo com os construtos originais, ficando agrupados em fatores identificados conforme o Quadro 4, a seguir. Segundo Hair Jr et al (2005), na matriz, deve-se: (1) observar as cargas fatoriais de cada variável e (2) identificar as variáveis que apresentam elevadas cargas fatoriais em ambos os componentes, no caso, valores acima de 0,40 . Esses autores sugerem que um dos pressupostos da análise fatorial é a estrutura simples de seus componentes. Para esses autores, em amostras de até 200 observações, como a desta investigação, tem-se 0,40 como o limite aceitável da contribuição da variável na criação do fator, com o objetivo de evitar o problema da indeterminação da relação entre variáveis e fatores.

Quadro 4 - Fatores extraídos e agrupados

\begin{tabular}{|l|l|}
\hline Fator & Variáveis observadas \\
\hline & mcs 4 - é importante para mim que a comida que eu consumo diariamente seja boa \\
para minha pele, meus dentes e meu cabelo. \\
mcs 3 - é importante para mim que a comida que eu consumo diariamente seja nu- \\
tritiva. \\
Fator 1 - aspectos \\
ligados à saúde. & $\begin{array}{l}\text { tenha saudável. } \\
\text { tes 5 - acredito que seja importante saber bem como se alimentar de maneira sau- } \\
\text { dável. } \\
\text { atma 5 - pratico ações de preservação ambiental. } \\
\text { mcs 9 - estou preparado para abdicar de muitas coisas e me alimentar da maneira } \\
\text { mais saudável possível. }\end{array}$ \\
\hline
\end{tabular}




\begin{tabular}{|c|c|}
\hline Fator & Variáveis observadas \\
\hline $\begin{array}{l}\text { Fator } 2 \text { - atitudes } \\
\text { quanto à compra } \\
\text { de orgânicos. }\end{array}$ & $\begin{array}{l}\text { atc } 3 \text { - comprar flv orgânicos em vez dos convencionais faria eu me sentir como se } \\
\text { estivesse contribuindo para algo melhor. } \\
\text { atc } 1 \text { - comprar flv orgânicos em vez dos convencionais me faria sentir que estou fa- } \\
\text { zendo algo "politicamente correto". } \\
\text { atc } 2 \text { - comprar flv orgânicas em vez dos convencionais me faria sentir uma pessoa } \\
\text { melhor. } \\
\text { atc } 5 \text { - comprar flv orgânicas em vez dos convencionais seria... (tolice-sábio) }\end{array}$ \\
\hline $\begin{array}{l}\text { Fator } 3 \text { - atitudes } \\
\text { em relação aos ali- } \\
\text { mentos orgânicos. }\end{array}$ & $\begin{array}{l}\text { ato } 3 \text { - alimentos orgânicos são uma fraude. } \\
\text { ato } 1 \text { - alimentos orgânicos são mais saudáveis. } \\
\text { ato } 9 \text { - alimentos orgânicos são apenas moda. } \\
\text { atc } 4 \text { - comprar flv orgânicos em vez dos convencionais seria... (danoso-benefico). } \\
\text { atc } 6 \text { - comprar flv orgânicas em vez dos convencionais me faria sentir... (insatisfeito- } \\
\text { satisfeito) } \\
\text { ato } 2 \text { - alimentos orgânicos têm qualidade superior. }\end{array}$ \\
\hline $\begin{array}{l}\text { Fator } 4 \text { - pressão } \\
\text { social }\end{array}$ & $\begin{array}{l}\text { ns } 1 \text { - a maioria das pessoas que são importantes para mim acha que eu deve- } \\
\text { ria } \begin{array}{l}\text { alimentos orgânicos. (evitar-comprar). } \\
\text { ns } 2 \text { - grande parte das pessoas próximas a mim acha que eu deveria } \\
\text { alimentos orgânicos. (evitar-comprar). }\end{array}\end{array}$ \\
\hline $\begin{array}{l}\text { Fator } 5 \text { - aspectos } \\
\text { ligados à saúde. }\end{array}$ & $\begin{array}{l}\text { mcs } 7 \text { - não fico o tempo todo me perguntando se as coisas que eu como são boas } \\
\text { pra mim. } \\
\text { mcs } 6 \text { - tenho a impressão de que as outras pessoas prestam mais atenção à sua saú- } \\
\text { de do que eu. } \\
\text { mcs } 2 \text { - eu realmente não fico pensando o tempo todo se tudo o que eu faço é sau- } \\
\text { dável. }\end{array}$ \\
\hline $\begin{array}{l}\text { Fator } 6 \text { - atitudes } \\
\text { em relação ao } \\
\text { meio ambiente. }\end{array}$ & $\begin{array}{l}\text { que façamos algo, os danos amb } \\
\text { olvimento atual está destruindo }\end{array}$ \\
\hline $\begin{array}{l}\text { Fator } 7 \\
\text { ções d }\end{array}$ & $\begin{array}{l}\text { ic } 2 \text { - eu pretendo comprar FLV orgânicos nos próximos quinze dias. } \\
\text { ic } 1 \text { - eu planejo consumir FLV orgânicos em breve. }\end{array}$ \\
\hline $\begin{array}{l}\text { Fator } 8 \text { - percep- } \\
\text { ção do controle de } \\
\text { compra. }\end{array}$ & $\begin{array}{l}\text { ccp } 1 \text { - se frutas, legumes e verduras orgânicos estiverem disponíveis para compra, } \\
\text { nada me impediria de comprá-los, caso eu quisesse. } \\
\text { ccp } 3 \text { - se eu quisesse, eu poderia facilmente comprar frutas, legumes e verduras or- } \\
\text { gânicas ao invés dos convencionais. }\end{array}$ \\
\hline $\begin{array}{l}\text { Fator } 9 \text { - meio am- } \\
\text { biente e controle } \\
\text { de compra. }\end{array}$ & $\begin{array}{l}\text { atma } 2 \text { - prefiro consumir produtos reciclados. } \\
\text { ccp } 2 \text { - eu tenho total controle sobre uma eventual compra de frutas, legumes e ver- } \\
\text { duras orgânicos. }\end{array}$ \\
\hline
\end{tabular}

O construto "Motivações e crenças ligadas aos orgânicos" ficou fortemente concentrado no Fator 1, com três variáveis no Fator 5 . O Fator 2 contém exclusivamente os itens constantes do construto "atitudes em relação a compra de orgânicos", embora haja uma redução de seis para quatro itens. O Fator 3 contém, em sua maioria, os itens do construto "atitudes em relação aos orgânicos", embora apresente dois itens do construto anteriormente mencionado. O Fator 4 agrupou exatamente os dois itens referentes ao construto "normas subjetivas"; os Fatores $6 \mathrm{e}$ 9 distribuíram os itens relativos ao construto "Atitudes em relação ao meio ambiente". O Fator 7 também agrupou perfeitamente os itens do construto "Intenções de compra".

Por fim, o Fator 8 agrupou, em sua totalidade, os itens do construto "Controle comportamental percebido", exceto por um item, que foi alocado no Fator 9. Pode-se observar, portanto, que ocorreu um agrupamento moderadamente relacionado aos construtos das perguntas realizadas.

\section{CONCLUSÕES}

No tocante à amostra investigada, revelou-se, entre os pesquisados, uma predominância de pessoas do sexo feminino. Tal dado corrobora com outras investigações, que apresentam esse gênero como o predominante. A maior parcela dos entrevistados declarou ter escolaridade 
em nível superior, e, dentre estes, o número de pós-graduados também apresentou nível significativo. A renda familiar também se revelou elevada, com a maioria dos entrevistados alocados entre os que a declaram acima de 3.000 reais mensais. A grande parte dos entrevistados é casada. No tangente ao número de pessoas morando na residência do entrevistado, a maioria declarou três pessoas, apenas $7 \%$ dos entrevistados moram sozinhos.

Em relação à compra dos orgânicos, os supermercados se revelaram como o ponto de venda principal. O mercado fortalezense, apesar da solidez da proposta das feiras agroecológicas, ainda é carente de pontos de venda extra aos supermercados. Membros da amostra para o pré-teste declararam, informalmente, nem saber da existência das feiras. Constatou-se um ligeiro equilíbrio entre os respondentes que declararam comprar semanalmente e aqueles que declararam comprar apenas de vez em quando. Os que compram diariamente representam o menor percentual do total de entrevistados. Esse dado vale, lembrar, está associado à compra de frutas, verduras e legumes.

As informações resultantes das análises dos dados coletados sugerem que os fatores que influenciam de forma mais precisa a compra de orgânicos pelos consumidores são fatores ligados ao construto motivações e crenças ligadas à saúde, construto que apresentou itens com cargas fatoriais mais elevadas. A amostra pesquisada buscaria, assim, o consumo de frutas, legumes e verduras orgânicos, tendo em vista a preocupação com a saúde, a maior percepção de qualidade oferecida, e todo um conjunto de crenças sobre benefícios proporcionados por esses produtos.

Não obstante a preocupação com o rigor metodológico empregado neste estudo, é importante ressaltar que algumas limitações lhe foram inerentes. $O$ instrumento de coleta adotado na pesquisa, por exemplo, é originário de fontes diversas, embora todos voltados para o mesmo fim. Ainda que as pesquisas que alimentam este artigo também, em sua maioria, tenham utilizado a compilação de questões para formarem as suas próprias, deve ser levado em conta que contextos culturais diversos podem implicar não ajustamento de itens específicos em contextos particulares.

Sob o ponto de vista gerencial, as contribuições que este estudo faze submergir envolvem o suporte na compreensão das variáveis determinantes do comportamento de um mercado ainda considerado novo e, portanto, passível de expansão e lucro econômico. Sugere-se, assim, aos agentes da cadeia produtiva, uma base para a formulação, escolha e implementação de estratégias adequadas ao mercado local, dando subsídios para que estes agentes (agricultores, fabricantes e varejistas) construam valor sobre esses produtos, direcionando esforços, inclusive de comunicação e de política de preços, voltados para o que tem valor percebido para os consumidores.

O caráter multidisciplinar e contemporâneo, característico do consumo aqui pesquisado, sugere reflexões que vão além do consumo saudável, pois acaba por abranger, de uma forma ou de outra, todo um sistema integrado, inclusive, natural, político e social. Sugere-se, para pesquisas futuras, a introdução de outras variáveis, que possam influenciar direta ou indiretamente o comportamento do consumidor frente aos produtos orgânicos. 


\section{REFERÊNCIAS}

AERTSENS, J.; VERBEKE, W.; MONDELAERS, K.; HUYLENBROECK, Guido Van. Personal determinants of organic food consumption: a review. British Food Journal. v. 111, n. 10, pp. 1140-1167, 2009.

AJZEN, I. Consumer attitudes and behavior. In: HAUGTVEDT, C. P.; HERR, P. M.; CARDES, F. R. (Eds.). Handbook of consumer psychology. New York: Lawrence Erlbaum Associates, 2008. Cap. 20.

The theory of planned behavior. Organizational behavior and the human decision process, v. 50, p. 179-211, 1991.

ANNETT, L.E.; MURALIDHARAN, V.; BOXALL, P.C.; CASH, S.B.; WISMER, W.V. Influence of Health and Environmental Information on Hedonic Evaluation of Organic and Conventional Bread. Journal of Food Science. v. 73, n. 4, 2008.

BECKER, M. H.; MAIMAN, L. A.; KIRSCHT, J. P.; HAEFNER, D. P.; DRACHMAN, R. H. The health belief model and prediction of dietary compliance: a field experiment. Journal of Health and Social Behavior. v. 18, n. 4, pp. 348-66, 1977.

BRASIL. Lei no 10831, de 23 de dezembro de 2003. Diário Oficial da República Federativa do Brasil, Brasília, DF, 23 dez. 2003. Disponível em: <http:// www.planalto.gov.br/ccivil_03/Leis/2003/L10. 831.htm>. Acesso em 3 mar. 2011.

. Decreto $\mathrm{n}-6.323$, de 27 de dezembro de 2007. Regulamenta a Lei no 10.831, de 23 dedezembro de 2003, que dispõe sobre a agricultura orgânica, e dá outras providências. Diário Oficial da União, Brasília, 27 dez. 2007. Disponível em: <http://extranet.agricultura. gov.br/sislegis-consulta/consultarLegislacao. do>. Acesso em: 10mar. 2011.

BRITO, V. Semana de orgânicos foca a identificação dos produtos. Agência Sebrae de Notícias. 05/11. Disponível em: <http://www. agenciasebrae.com.br/noticia/11941390/ agronegocios/semana-de-organicos-foca-aidentificacao-dos-produtos/ >. Acesso em: 02 ago. 2011.

CAHILL, S.; MORLEY, K.; POWELL, D. A. Coverage of organic agriculture in north America newspapers- media: linking food safety, the environment, human health and organic agriculture. British Food Journal, v. 112, n. 7, pp. 710-722, 2010.

CHEN, M. F. Consumer attitudes and purchase intentions in relation to organic foods in Taiwan: moderating effects of food-related personality traits. Food Quality and Preference. v. 18 n. 7, pp. 1008-1021, 2007.

DUNLAP, R. E; SCARCE, R. The Polls-Poll Trends: Environmental Problems and Protection. Public Opinion Quarterly, v. 55, p. 651-672, 1991.

ESSOUSSI, L.H.; ZAHAF, M. Exploring the decision-making process of Canadian organic food consumers: motivations and trust issues. Qualitative Market Research: an international Journal, v.12, n.4, pp. 443-459, 2009.

FLORES, M. Produção de orgânicos deve crescer 40\% em 2011. Agência Sebrae de Notícias. 06/11. Disponivel em:<http://www.agenciasebrae.com. br/noticia/11962062/agronegocios/producaode-organicos-deve-crescer-40-em-2011/>. Acesso em: 02 ago. 2011.

GIL, J.M.; GRACIA, A.; SANCHEZ, M. Market segmentation and willingness to pay for organic products in Spain. International Food and Agribusiness Management Review, v. 3, pp. 207-26, 2000.

HANSEN, T.; MUKHERJEE, A.; THOMSEN, T. U. Anxiety and search during food choice: the moderating role of attitude towards nutritional claims. Journal of Consumer Marketing. v. 28, n.3 , pp. 178-186, 2011.

HAIR JR.J.F; ANDERSON, R. E.; TATHAM, R. L.; BLACK, W. C. Análise multivariada de dados. 5. ed. Porto Alegre: Bookman, 2005. 
HAYES, D.; ROSS, C. E. Concern with Appearance, Health Beliefs, and Eating Habits. Journal of Health and Social Behavior, v. 28, pp.120-130, 1987.

HOPPE, A. Comportamento do Consumidor de produtos orgânicos em Porto Alegre em dois canais de distribuição. 2010. 130 f. Dissertação (Mestrado) - Universidade do Vale do Rio dos Sinos, Programa de Pós-Graduação em Administração, 2010.

JONES, P.; CLARKE-HILL, C.; SHEARS, P.; HILLIER, D. Case study - Retailing organic foods, British Food Journal, v. 103, n. 5, pp. 358-365, 2001.

KRISCHKE, P.; TOMIELLO, N.. O comportamento de compra dos consumidores de alimentos orgânicos: um estudo exploratório. Cadernos de Pesquisa Interdisciplinar em Ciências Humanas, v. 10, n. 96, p. 27-43, 2009.

MAGKOS, F.; ARVANITI, F.; ZAMPELAS; A. Organic Food: buying more safety or just peace of mind? A critical review of the literature. Critical Reviews in Food Science and Nutrition, v. 46, pp. 23-56, 2006.

MAGNUSSON, M. K.; ARVOLA, A.; KOIVISTO HURSTI, U-K.; ABERG, L.; SJÖDÉN, P.-O. Choice of organic foods is related to perceived consequences for human health and to environmentally friendly behaviour. Appetite, v. 40, pp. 109-117, 2003.

MAHÉ, T. Are stated preferences confirmed by purchasing behaviours? The case of fair tradecertified bananas in Switzerland. Journal of Business Ethics. v. 92, Supplement 2, pp. 301-315, 2010.

MATIAS, B. Brasil pode ser porta de entrada de orgânicos. 07/11. Agência Sebrae de notícias. Disponível em: http://www.agenciasebrae. com.br/noticia/12147288/agronegocios/ brasil-pode-ser-porta-de-entrada-deorganicos/>. Acesso em 01 ago. 2011.

ÖZCELIK, A. Ö.; UÇAR, A. Turkish academic staffs' perception of organic foods. British Food Journal. v. 110, n. 9, pp. 948 - 960, 2008.
PADEL, S.; FOSTER, C. Exploring the gap between attitudes and behaviour - understanding why consumers buy or do not buy organic food. British Food Journal. v. 107, n. 8, pp. 606-25, 2005.

SAHER, M.; LINDERMAN, M.; ULLA-KAISA, K. $\mathrm{H}$. Attitudes towards genetically modified and organic foods. Appetite. v.46, pp. 324-331, 2006.

SCHIFFERSTEIN, H. N. J.; OUDE OPHUIS, P. A. $M$. Health-related determinants of organic food consumption in The Netherlands. Food Quality and Preference, v. 9, pp. 119-33, 1998.

SHAHARUDIN, M. R.; MANSOR, J. W.; ELIAS, S. J. Purchase Intention of Organic Food; Perceived Value Overview. Canadian Social Science. v. 6, n. 1, pp. 70-79, 2010.

TARRANT, M.; CORDELL, K. The effects of respondent characteristics on environmental attitude-behavior correspondence. The Journal of Environmental Education, v. 29, p. 618-637, 1997.

TSAKIRIDOU, E.; BOUTSOUKI, C.; ZOTOS, Y.; MATTAS, K. Attitudes and behavior towards organic products: an exploratory study. International Journal of Retail \& Distribution Management, v. 36, n. 2, pp. 158-175, 2008.

WANDEL, M.; BUGGE, A. Environmental concern in consumer evaluation of food quality. Food Quality and Preference. v. 8, n. 1, pp. 19-26, 1997.

WINTER, C. K.; DAVIS, S. F. Organic Foods. Journal of Food Science, v. 71, n.9, pp. 117124, 2006.

ZAKOWSKA-BIEMANS, S. Polish consumer food choices and beliefs about organic food. British Food Journal. v.113, n. 1, pp. 122-137, 2011.

ZANOLI, R.; NASPETTI, S. Consumer motivations in the purchase of organic food - a means-end approach. British Food Journal, v. 104, n. 8, pp. 643-53, 2004. 
